\title{
Infrastructural Cyber-Physical Energy Systems: Transformations, Challenges, Future Appearance
}

\author{
N.I. Voropai* ${ }^{*}$ V.A. Stennikov, S.M. Senderov
}

Melentiev Energy Systems Institute of Siberian Branch of Russian Academy of Sciences, Irkutsk, Russia

\begin{abstract}
The directions for the transformation of the key hierarchically-structured infrastructure energy systems, i.e., electric power, heating, and gas supply systems, as influenced by intensively expanding adoption of technology innovations in physical (power) and information-and-communication subsystems are studied. The peculiarities of the transformation of the energy systems structure at their different hierarchical levels are analyzed. Changes in the properties of future energy systems as influenced by innovation-driven processes and facilities are discussed. Interpretations of new properties of transforming energy systems, i.e. flexibility and resiliency, which have recently been the subject of much research effort are analyzed. It is argued that in the future the above energy systems will acquire the features of integrated cyber-physical systems. The fundamental role of developing control systems for future infrastructure cyber-physical energy systems is emphasized.
\end{abstract}

Index Terms: Infrastructural energy systems, hierarchical designs, technology innovations, transformation, structure, properties, cyber-physical systems, control.

\section{INTRODUCTION}

The key energy infrastructure systems are electric power systems (EPS), heating systems (HS), and gas supply systems (GSS). They have an elaborate multi-level structure and play a crucial role in ensuring a guaranteed energy supply to consumers with their increased requirement for reliability and quality of energy supply in accordance with the new paradigm of user-oriented energy systems. By way of illustration, Figure 1 [1] presents the structure of the EPS as a super-mini-micro-system

\footnotetext{
${ }^{*}$ Corresponding author.

E-mail: voropai@isem.irk.ru
}

http://dx.doi.org/10.38028/esr.2020.03.0003

Received June26 18, 2020. Revised July 25, 2020.

Accepted August 11, 2020. Available online December 27, 2020.

This is an open access article under a Creative Commons Attribution-NonCommercial 4.0 International License.

(C) 2020 ESI SB RAS and authors. All rights reserved. where level of the super-system incorporates large power plants, system energy storages of large capacity, and main electrical power network of high and ultra-high voltages; the level of the mini-system is that of mini-sources of the electric power up to $25 \mathrm{MW}$ of unit capacity, mini-storages, and the distribution network of $6-110 \mathrm{kV}$; the level of the micro-system subsumes micro-sources and micro-storages of the electric power of unit capacity up to $25 \mathrm{~kW}$ and the local power grid of $0.4-10 \mathrm{kV}$.

Heating systems differ from electric power and gas supply systems only in their scale and location in urban areas. They are structured as a hierarchical system as well (Figure 2) and are differentiated into super-systems that cover large heat sources (combined heat and power (CHP)) plants, boilers, etc. with a capacity above $25 \mathrm{Gcal} /$ hour), transit and main heat networks (HN) coming from them, mini-systems with a heat capacity below $25 \mathrm{Gcal} /$ hour as part of heat sources (cogeneration plants, boilers, nonconventional and renewable energy sources), distribution networks of small diameters and individual heat points, and micro-systems in the form of individual non-conventional and renewable energy sources built directly at one or several consumers with their heat consumption systems, as well as micro-systems of buildings and structures.

As for GSSs, at the level of the super-system one should deal with process facilities that supply gas to the network of its supply mains, starting from the fields and main compressor stations at the field outlets and down to the points of its delivery to gas distribution stations and units. The main facilities of GSSs at this level are main and intermediate compressor stations, high pressure gas trunklines, and underground gas storage facilities that compensate for seasonal unevenness of gas consumption. The share of natural gas transportation allotted to liquefied natural gas (LNG) transport, mostly via waterways as shipped by gas carriers, is ever increasing. At the same time, natural gas liquefaction plants, tankers, and regasification terminals themselves should also be counted as belonging to the facilities of the GSS super-system.

At the level of the GSS mini-system, one should consider gas distribution networks of high pressure (0.3 to $1.2 \mathrm{MPa})$ from gas distribution stations, as well as medium (0.05 to $0.3 \mathrm{MPa}$ ) and low (up to $0.05 \mathrm{MPa}$ ) pressure networks 


\section{Super-Mini-Micro Grid Structure}

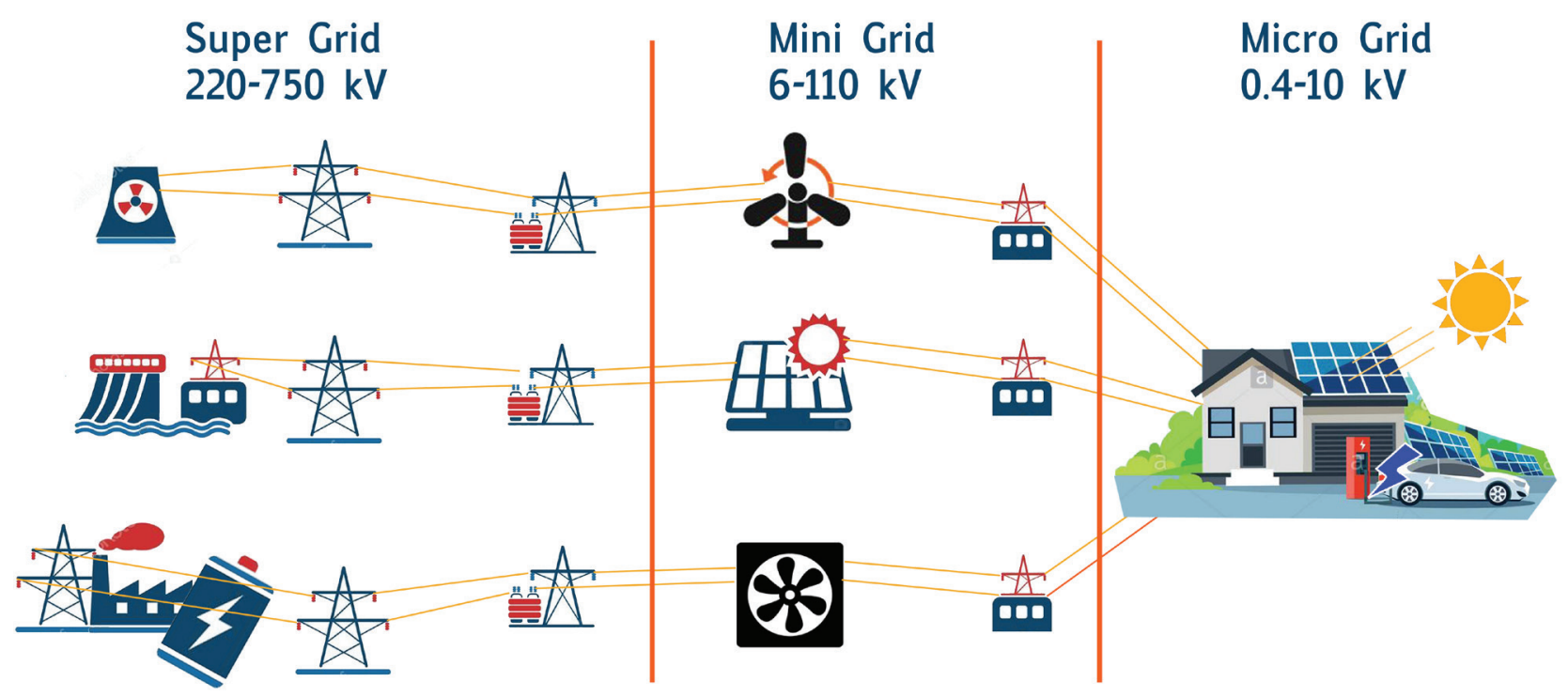

Fig. 1. Super-mini-micro-electric power system.

from gas distribution units down to shut-off devices at the inlets to gas-fired thermal power plants, boilers houses, gas chemical complexes, and buildings with gas equipment. Moreover, at this level one should take into account the systems of discrete transport (primarily road transport) of liquefied and compressed natural gas. The level of microsystems is represented by internal gas pipelines running from their entries into buildings and structures to connection points of consuming devices and appliances: gas boilers, turbines, equipment of gas-chemical enterprises, and other gas-consuming gas receivers.

The above energy systems in the process of development are transformed in terms of their structure and properties due to the expanding adoption of technology innovations in production, transport, distribution, storage, and consumption of energy, intensive development of renewable energy sources, as well as the activity of consumers in the processes of their energy supply, etc.

This study analyzes the main directions of transformation of the structure and properties of future EPSs, HSs, and GSSs, discusses the transformation trends these energy systems have in common and their unique features, as well as topical problems and challenges associated with the discussed trends that determine the future appearance of these key infrastructure systems.

Taking into account the above-mentioned specific features of infrastructural energy systems, Chapter 2 of this paper deals with the structural trends in energy systems development. The transformation of energy systems properties is discussed in Chapter 3. Integrated cyber-physical energy systems of the future are the focus of Chapter 4. Directions of control systems development for integrated energy systems are discussed in Chapter 5. Some conclusions are presented in Chapter 6.

\section{STRUCTURAL TRENDS IN ENERGY SYSTEMS DEVELOPMENT}

\section{A. Electric power systems}

Trends in the transformation of the EPS structure at the super-system level are determined by a number of long-established and emerging factors. The key longestablished factor is the realization of system effects from the joint operation of EPSs, that are considered as system services. The Association of System Operators of the world's largest EPSs G015 draws attention to the need for a new understanding of such system services under market conditions [2].

A relatively new factor is the formation of megacenters of power generation with the use of renewable energy resources, such as the largest hydroelectric power plants - HPP (the "Three Gorges" HPP on the Yangtze River in China, a large-scale hydroelectric power plant on the Congo River in Central Africa, etc.), mega-parks of wind power plants in the North Sea and the Arctic coast of Russia, solar power plants in the Sahara and Gobi deserts, and others. By way of illustration Figure 3 shows a mega-project for the development of Western European Interconnection based on wind parks in the North Sea and solar power plant parks in the Sahara desert [3].

Electricity generated by these mega-centers should be distributed over ultra-long distances, which is feasible given the active development and reduction of the cost of long-distance power transmission technologies of ultrahigh AC and DC voltages. This served as the basis for the 


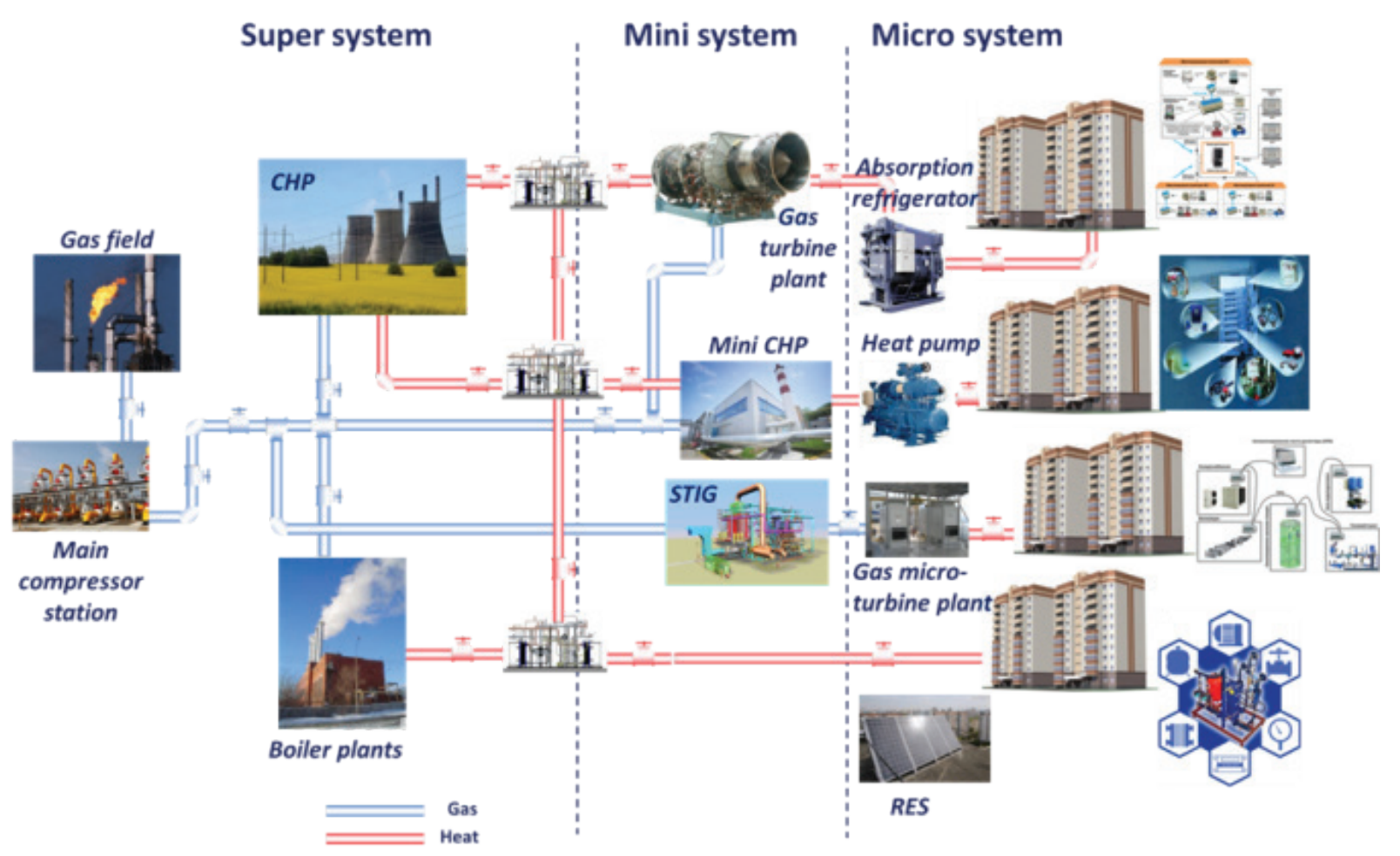

Fig. 2. Super-mini-micro-heating system.

proposal to form the Global Energy Interconnection (see Figure 4) [4].

On the other hand, active development of distributed generation continues, which radically redefines the structure and properties of mini-systems. However, the sometimes proposed extreme scenario of EPS development that makes use of distributed generation only when major power plants are withdrawn from operation seems unrealistic. The mixed scenario of development of relatively large power plants at the level of super-systems (centralized power supply) and distributed generation units at the level of mini-systems (decentralized power supply) has a high probability of implementation success. The function of power supply of large consumers remains the responsibility of large centralized sources, which is practically impossible to attain by means of distributed generation, along with ensuring the reliability of power supply and quality of electricity in terms of frequency and voltage.

The general structural trend for super-systems and mini-systems is the continuing increase in the density and complexity of main and distribution power networks. The structure of large EPSs is becoming more and more heterogeneous, with cases of system "voltage-wise" instability in concentrated parts of the EPS being more and more probable, while the problems of "angle-wise" instability in its extended parts with long electrical connections persevere.

The growing complexity of the structure of developing EPSs with the general growth of installed capacity and scale of EPSs lead to the more devastating aftermath of severe system accidents of cascade nature, which is confirmed, in particular, by the US EPS historical data for 1991-2005, shown [5] (see Figure 5).

Micro-systems have traditionally been formed as based on alternating current. Nowadays, many electrical receivers operate on direct current. Rectifier-inverter units are used for their connection with the EPS. On this basis, DC micro-systems or hybrid DC/AC micro-systems are developed. The unique project of implementation of DC micro-systems is the program of power supply of isolated individual consumers of Mongolia "100,000 Solar Houses (gers)" [6].

Both stand-alone and joint operation of micro-systems with EPSs generates a number of urgent problems for studies on substantiation of micro-systems development and control of their operation under various conditions.

Thus, structural changes in EPSs at all three levelssuper-, mini-and micro-systems-lead to changes in their properties and new problems that are to be solved.

\section{B. Heating systems}

Heating systems, often integrated with electric power and gas supply systems through heat sources (CHP plants), heat networks, and consumers, stand out as relatively local in nature. In accordance with the energy policy of Russia, their development is aimed at the prevalence of district heating. In terms of capacity and production of thermal energy, they reach a large scale and therefore are aptly classified as large energy systems. Thus, the heating systems of Moscow in terms of capacity (over 52 thousand Gcal/h) and 


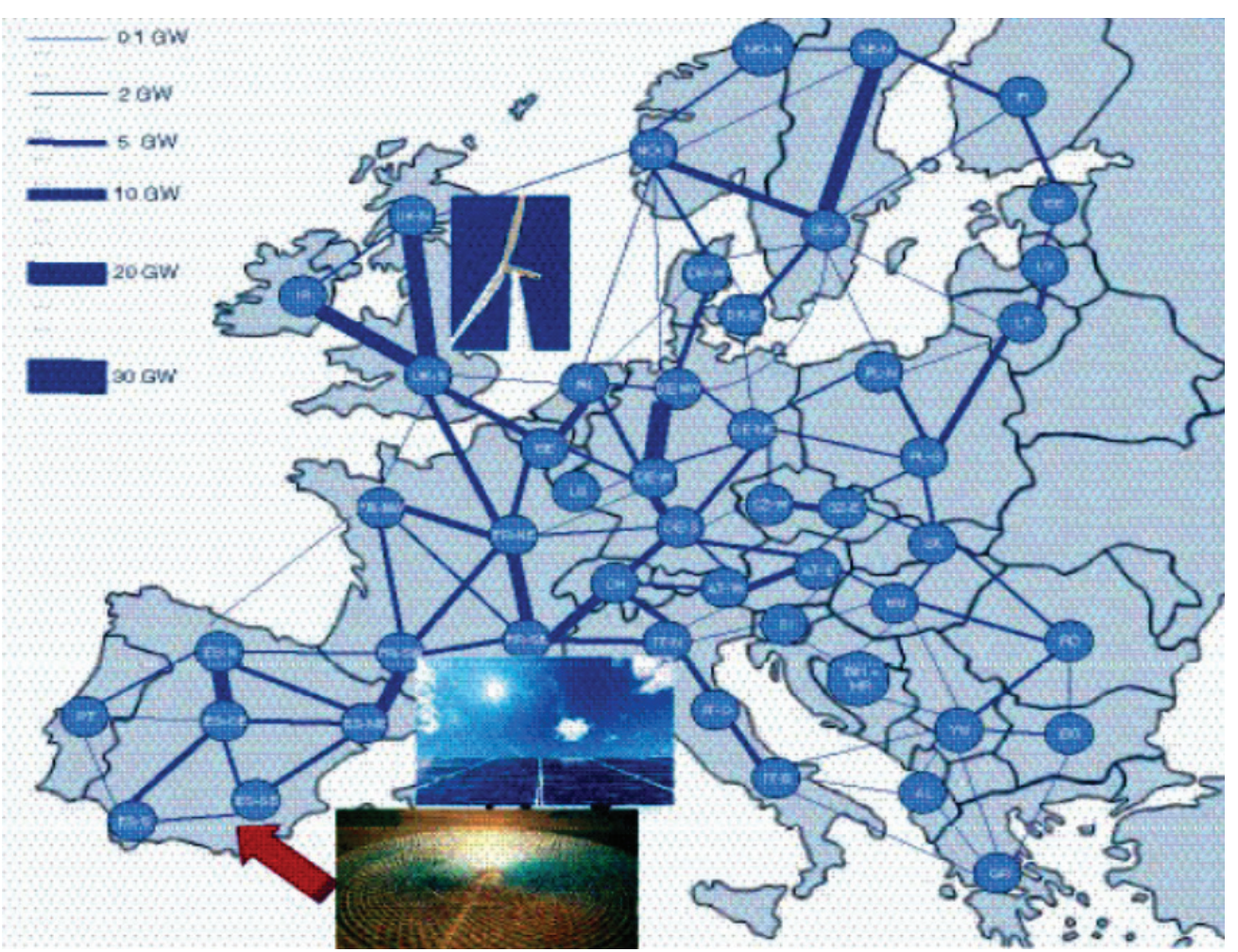

Fig. 3. Mega-project of West European interconnection development.

thermal energy production (over 95 million Gcal/year) exceed the HSs of such industrial regions as Irkutsk, Novosibirsk, Sverdlovsk regions, Krasnoyarsk Krai, etc. in terms of their size. All three process structures of systems (super-, mini-, and micro-systems) can exist either as part of a single centralized system, or separately, performing each their own functions.

Relatively new trends are manifested at all structural levels and are related not only to processes and equipment used in the systems of production, transport, and consumption of thermal energy, but also to changes in the processes of their operation, administration and control models (see Figure 6).

At the level of large systems, there is a growing tendency to merge scattered systems at the level of main heat networks with the organization of heat sources into unified HSs. Gas-powered steam-turbine CHP plants are being upgraded into combined cycle and gas turbine power plants based on cogeneration units. They have a wide power range depending on whether they belong to superor mini-systems. In both types of HSs, new materials (composites, metal-filled plastics, etc.) and modern technology of trenchless laying of thermal networks are actively adopted. The system of automation and regulation in heat networks at the consumer side undergoes significant changes, it is focused on providing remote control with variable regulation of heat transfer medium flows, with automated units for maintaining and altering pressure and flowrate values, monitoring of consumption level, and the possibility of its regulation.
A very pronounced trend of transformation can be seen at the level of mini- and micro-systems, in which nonmechanized manual labor is replaced by automation and regulation systems.

Structural transformations on the basis of the outlinebased division into subsystems (sources, networks, consumers) are accompanied by the transition to new technologies of systems operation in real-time and consumer activity.

Changes in the principles of construction and operation of the HSs being developed determine their structural complexity and require the appropriate development of methodological and theoretical support.

\section{Gas supply systems}

The main trends in the transformation of the GSS structure at the super-system level are related to the features of prospective changes in the structure of production, trunkline transport, and natural gas consumption.

As for the structure of gas consumption, it is based on various options for the development of energy consumption in the world, including Europe [7, 8, etc.], and even taking into account a significant anticipated growth of the role of renewable energy sources (RES) in the generation of electricity and heat (by 2040, RES may take up 15\% of the world fuel balance as compared to $3 \%$ today), it can be assumed that consumption of natural gas will not decrease at least until 2040, but it may also increase slightly due to the active development of the gas chemical industry. Of all regions of the world, the largest growth in gas consumption 


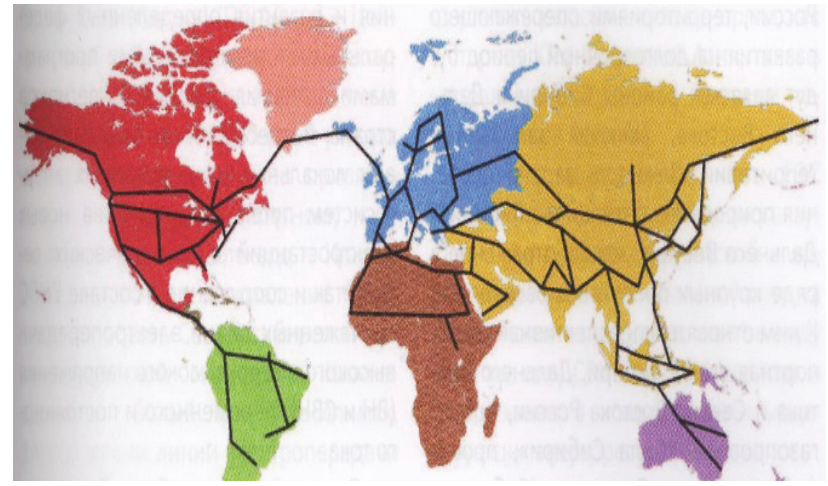

Fig. 4. Possible scenario of Global Energy Interconnection.

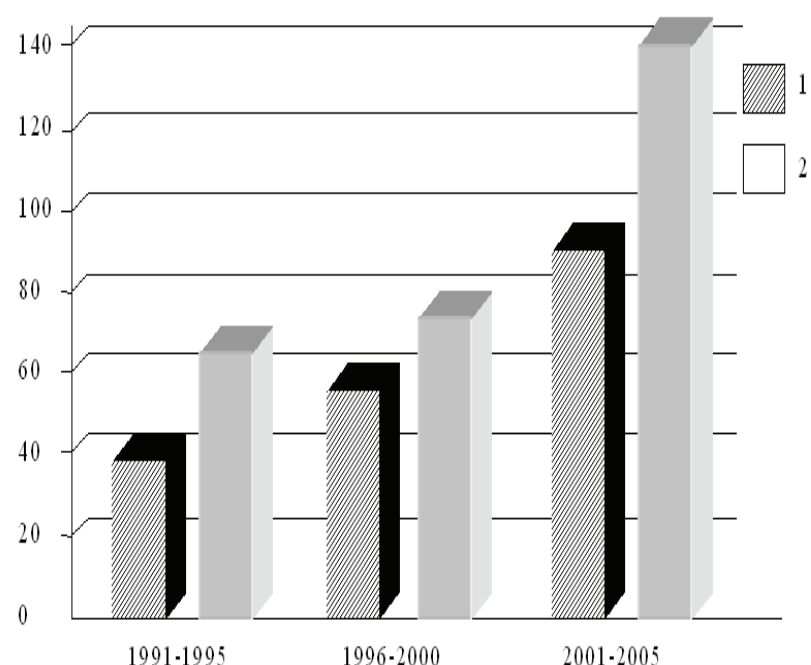

Fig. 5. Tendency for electric power system (EPS) blackout problems [25]. (1) The number of outages affecting more than 50,000 consumers; (2) The number of outages greater than $100 \mathrm{MW}$. will take place in developing but not yet sufficiently industrialized regions. Pipeline infrastructure in such regions of the world is undeveloped or non-existing. This creates prerequisites for active development of the LNG transportation system with further development of the natural gas liquefaction and regasification plants network. The same holds true for the entire world as well, where for reasons of lesser dependence of gas producers on binding to specific consumers, it seems that the mainstream LNG transportation by sea will be developing at a faster pace than pipeline transportation.

In this case, the main structural transformations may concern the increase of maneuverability in response to changes in supply and demand. For example, over the last few years natural gas shortages in the USA have been transfigured into its abundance, which led to the development of plans to expand the area of regasification terminals to establish natural gas liquefaction capacities [9, etc.]. Implementation of such projects in the world will allow both exporting and importing natural gas using the same infrastructure depending on the market situation.

As for the structure of natural gas production, due to the high level of development of already proven conventional gas-bearing fields, costly access to new fields located mostly in hard-to-reach conditions, and engineering challenges posed by shale gas extraction, as well as taking into account the environmental problems of this process, the technology behind gas production from gas hydrates and world ocean-dissolved gas is the most promising in the world. Estimates of methane content in gas hydrates in the world are huge and according to various estimates they reach several hundred trillion cubic meters [10, 11, etc.]. However, with all the successes of industrial and

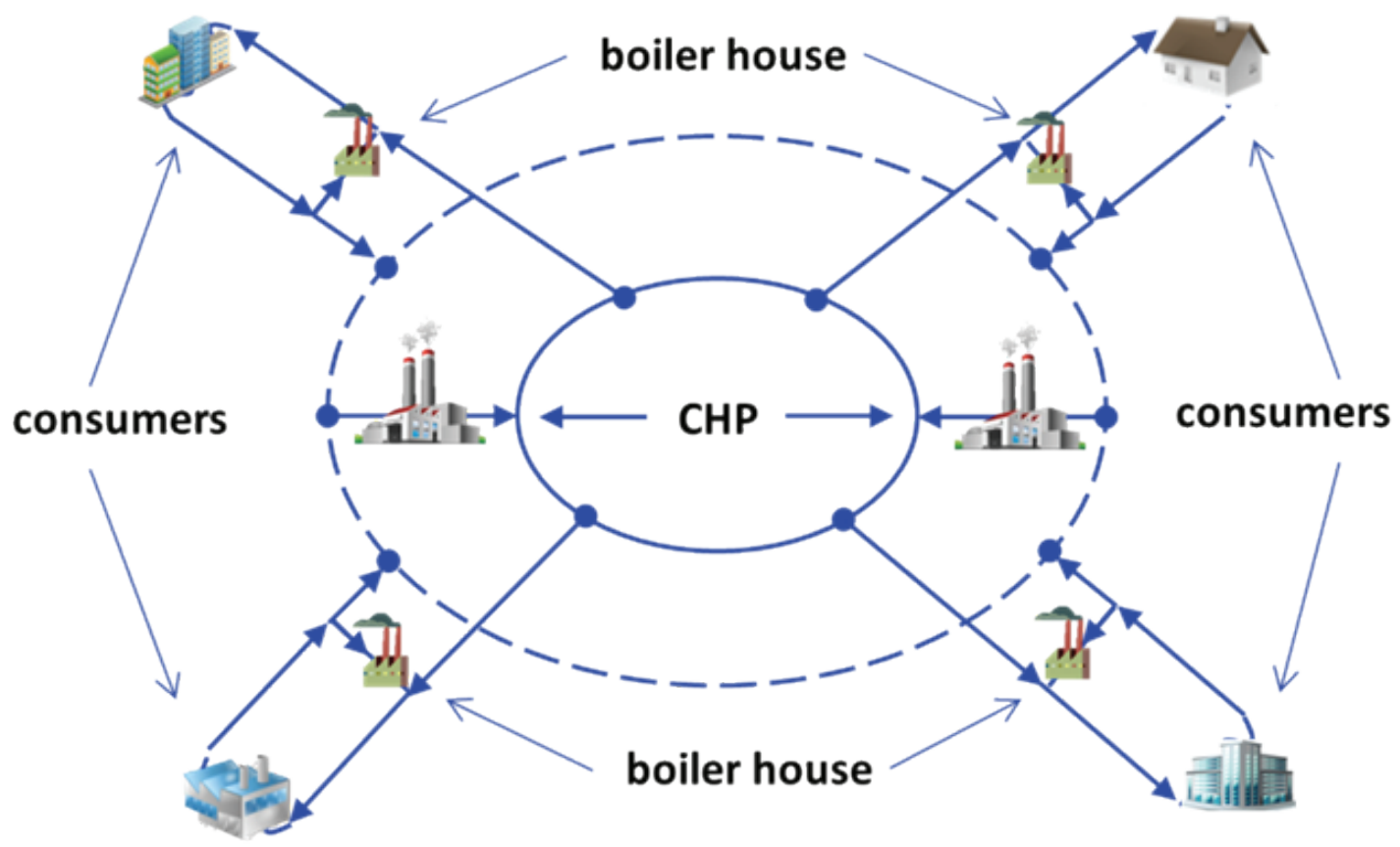

Figure 6. Heating plants interconnection for joint work on heating network 


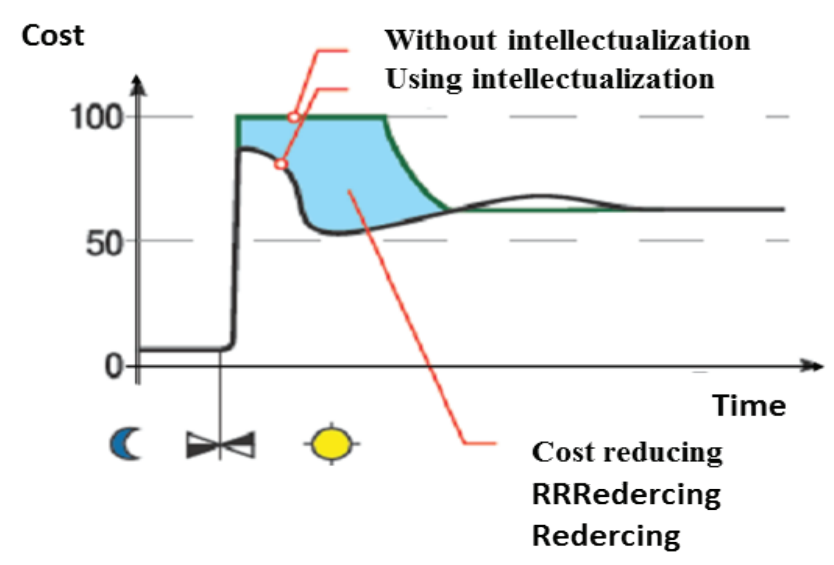

Fig. 7. Effect of HS intellectualization.

experimental extraction of methane from gas hydrates (the experiments run by teams from Japan and China, etc.) $[12$, etc. $]$ there are still obviously serious issues with the economic feasibility of extracting methane trapped inside the frozen lattice of gas hydrates molecules. This requires either lowering the pressure in the deposit, or heating the area near the well, or injecting carbon dioxide to replace methane in the hydrate. All these methods are still unacceptably expensive. In any case, humanity's quest for utilizing these resources will be answered in the future. The structure of sales gas production will shift towards gas hydrates development, and the gas trunkline system, in this case it is likely to be maritime LNG transport, will be tied to the point of its production facilities.

With potential changes in sources of sales gas supply due to depletion of the old fields and the need to access new ones, gas trunkline systems as well will undergo structural transformations. Individual gas trunklines tied to specific depleted fields will lose their relevance. One will have to build new gas trunklines tied specifically to new sources. Apparently, gas trunkline systems tied to regasification terminals and associated with LNG transportation via waterways will be developing at a faster pace. These terminals serve as gas suppliers to the gas pipeline network regardless of changes in gas production locations.

At the level of mini-systems of gas supply to the consumers, the GSS will change structurally in line with the scientific and engineering progress at the gas consumers side. Thus, as the share of NGV fuel use in transport increases, the networks of liquefied and compressed natural gas refueling will increase. Such refueling stations are adapted to the transport infrastructure and can be built at considerable distances from the gas transmission networks. Accordingly, the structure of discrete (road, railway, and water) transport of both LNG and compressed natural gas $(\mathrm{CNG})$ will be developing at a faster pace as the number of such refueling stations grows.

Micro-systems of gas supply are unlikely to undergo drastic structural changes in the future. In all likelihood, they will be the same pipeline distribution across buildings, enterprises, and facilities using innovative intelligent shutoff and control gas pipeline valves with the incorporations of various levels of smart systems to control the energy consumption of the respective consumers.

\section{TRANSFORMATION OF ENERGY SYSTEMS PROPERTIES UNDER THE IMPACT OF TECHNOLOGY INNOVATIONS}

\section{A. Electric power systems}

Recently, due to the broader adoption of generating units running on renewable energy resources, that are characterized by unsteady power output, and increased activity on the part consumers to control their own electricity consumption in real-time, the uncertainty of the current operation mode of the EPS has increased significantly, which encouraged the study of the flexibility of the EPS and justification of the means to increase it. The flexibility of the EPS is a relatively new concept characterizing its ability to maintain the normal or close to normal state under the influence of internal (sudden changes and fluctuations of generation and load, flows along lines) and external (random disturbances) random (uncertain) factors [13].

Modern EPSs while utilizing conventional energy and electrical power engineering technologies and control systems possess a sufficiently high level of flexibility due to the presence of self-adaptation and self-stabilization properties in relation to internal and external destabilizing factors. The above properties of the EPS are determined by the action of voltage/frequency governing effects of load, frequency characteristics of generators, as well as the inertia of rotating masses of rotors of synchronous and asynchronous machines, and the action of regulation and automation systems. Due to the presence of these properties, EPSs adapt to abrupt operation mode changes set within permissible limits, and when the operation mode parameters exceed permissible limits, the emergency control system comes into operation.

Electric power systems of the 21st century are undergoing significant changes in their properties not only due to the transformation of their structure but also due to the use of technology innovations in production, transport, storage, distribution, and consumption of the electric power. The factors internal to the EPS that significantly reduce the ability of systems to self-adaptation and self-stabilization are related to the mass use of power electronics and rectifier and inverter units for communication with the EPS of highspeed gas turbine and gas-reciprocating generators, wind turbines, photovoltaic units, electric energy storage, and frequency-controlled load motors.

The growth in the scale of the use of these technologies at the levels of super-systems and mini-systems significantly reduces the ability of the EPS to self-adapt and self-stabilize and, as a result, reduces the level of its flexibility. On the other hand, the growth of the share of randomly fluctuating generation on renewable energy resources (wind turbines, 


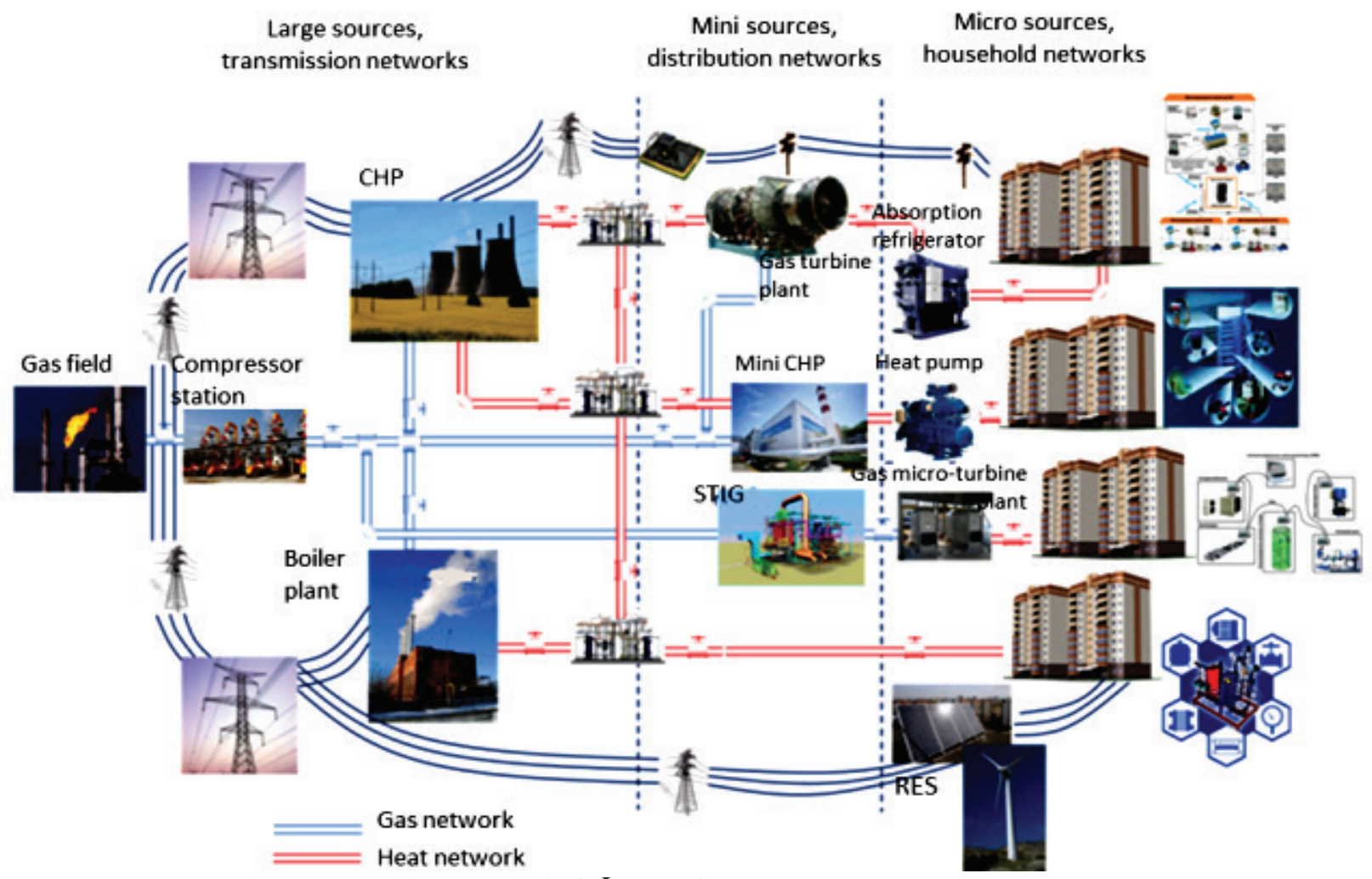

Fig. 8. Integrated energy systems.

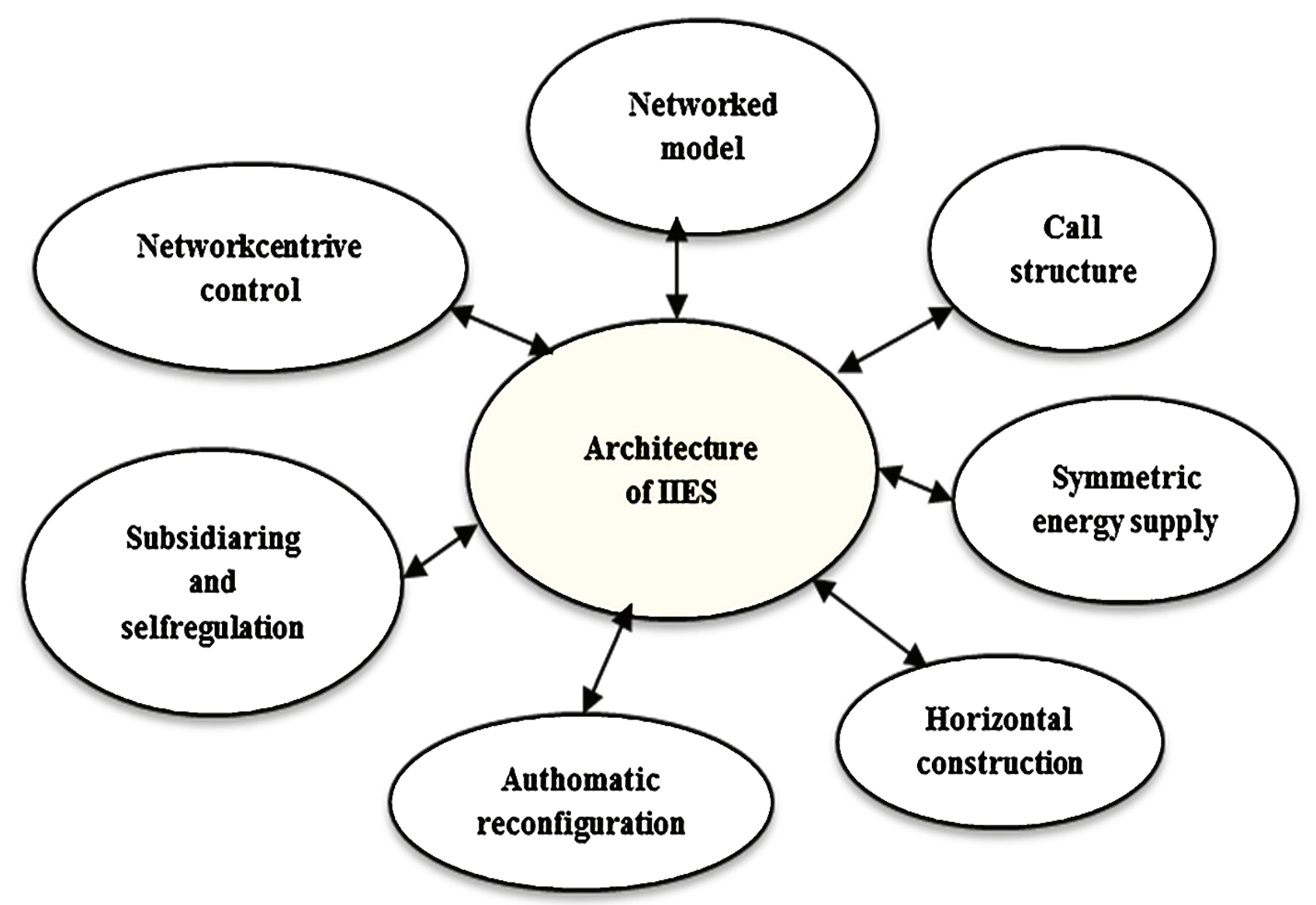

Fig. 9. Architecture of integrated intelligent energy systems. 
photovoltaic panels, small HPPs) also leads to a decrease in the flexibility of the EPS. At the same time, the control systems of many devices using power electronics (FACTS, energy storage, DC lines and links) have high efficiency of control and stabilization. Their wide adoption in future EPSs will ensure a drastic increase in controllability and, consequently, in flexibility of these systems.

In general, there are numerous possibilities for future EPSs to ensure their flexibility and to choose reasonable means for this purpose: this is a far from easy problem than can be solved for standard conditions of operation and development of these systems [13]. At the same time, the relevance of studies of off-standard (extreme) conditions under the impact of corresponding external and internal factors that require careful consideration increases. These factors are associated with the notion of EPS survivability [13], and recently with the closely related property of resiliency, which is considered in relation to large-scale disturbances and cascade accidents in EPSs [14, etc.]. To counteract such complex emergencies, the emergency control and protection system is available and is being developed, including effective procedures for restoring EPSs. An important role is relegated to regular dispatcher training sessions, as well as analysis and generalization of the nature and mechanisms of occurrence and development of such unique accidents.

\section{B. Heating systems}

Heating systems starting from the end of the 19th century to the present day have undergone the transformation in four generations. Heating in Russia is now at the stage of the transition from second- to third-generation systems, although European countries are already at the stage of development of systems of the fourth generation.

In order for domestic heating systems to level up, it is necessary to move from a single-loop system to a two- or three-loop system with individual intelligent heat consumption systems.

This will allow changing the technology of systems operation by advancing to the regulation of heating to consumers in real-time, which will complement the energy-consuming centralized regulation with local and individual settings and will provide an opportunity to strengthen existing and implementing new properties such as flexibility (adaptation to the current level of energy consumption); customer-centricity (the ability of the system to respond to consumer demands); integration (integration into the urban infrastructure); efficiency (compliance with energy efficiency requirements); competitiveness (economic advantage); reliability (meeting the growing energy demand, resistance to accidents), interoperability (the ability of subsystems and their elements to exchange energy and information so as to attain the maximum gains), etc.

Technological transformations of HSs will allow implementing other properties listed above that are typical also of electric power and gas supply systems and various types of their structures.

An important change in the properties of the energy systems under consideration is the transition from a unidirectional (from the source down to the consumer) scheme of movement of energy flows to a multidirectional one (i.e., with flows in multiple directions). This increases the mobility of HSs, their maneuverability, implements the bilateral nature of supply to consumers, significantly enhancing the property of reliability of heating, but at the same time, it gets way more difficult to control their development and operation. The transition from systems with high inertia of the process to flexible informationand-energy structures controlled in real-time seems to be the key for HSs, which provides them with quality performance of their functions with respect to heating provided to consumers while reducing energy and financial costs (see Fig.7).

\section{Gas supply systems}

Under the influence of technology innovations, the properties of GSSs are transformed at all levels considered herein, from fields and facilities of sales gas production to the processes of its use.

Thus, the concept of the intelligent gas field as a system of automatic control of gas production operations, which provides for automatic optimization of all the most important technological processes in their direct interrelationships, is already beginning to be implemented in practice. The pros of the introduction of this concept are expressed in the emergence of a new property of facilities and the system as a whole, that of a possibility of remote control. It also provides opportunities to monitor energy consumption, improve the efficiency of equipment operation and deliverability of wells through the monitoring and regulation of well yields, the prediction parameters of well exhaustion based on machine learning methods, forecasting of the behavior of new wells, centralized control of a large number of wells through remote monitoring systems, rational personnel management, and transparency of information.

As for improving the reliability of the operation of the line pipe section of the GSS, the so-called "intelligent tieins" or remote monitoring system for the strain-stress state of pipelines are already being adopted at newly constructed and reconstructed gas trunklines. Such systems are tied into the gas pipeline and allow monitoring mechanical loads by comparing them against current strength characteristics of the pipe. Their use proves feasible both in the gas trunklines themselves and in the piping of compressor and gas distribution stations, etc. Incidentally, cathodic protection parameters of gas pipelines are also monitored.

Such a concept can be applied to the full extent, with consideration of the respective differences, at all levels of the GSS. As a result of all these innovations, individual elements of the system and the entire GSS system as a 
whole have significantly increased their reliability. It is achieved by means of receiving reliable information on the state of elements of the system, arriving at optimum parameters of their operation and systems of protection against negative influences (galvanic corrosion, etc.), and also the possibility of timely decision-making when it is required to take preventive measures on maintenance of the pre-defined level of operability of the GSS.

All that having been said, at the micro-level, novel technologies will also have a positive impact on the energy efficiency of consumer processes, incorporating them into a common friendly interface between gas suppliers and consumers, within the framework of intelligent energy consumption processes, both for process and domestic needs.

\section{INTEGRATED CYBER-PHYSICAL ENERGY SYSTEMS OF THE FUTURE}

\section{A. Integrated intelligent energy systems}

The current objectively observable trends in the development of energy infrastructural systems are characterized by their tighter integration at the levels of production and consumption of energy and energy resources (see Fig.8) [1, etc.]. The processes of integration of electric power, heating, and gas supply systems into a meta-system increase its level of integrity and organization while contributing to the higher volume and intensity of relationships and interactions between individual systems. As a result, a high level of comfort in residential, public, and production buildings is achieved, including quantitative and qualitative growth of the array of energy services (related to electric power, heating, and gas supply) at an affordable price; ensuring controllability, reliability, safety, and efficiency of energy systems; reducing their negative impact on the environment, including greenhouse gas emissions. Combining multiple energy systems into a single energy and process meta-system with a common coordinated control system yields a synergistic effect in many aspects.

An integral property of such an integrated meta-system is its intelligent nature. It is based on the agent-based paradigm: each consumer, receiving information through its intelligent agents about all other participants in the energy supply process, determines its own behavior.

The technology of intelligent meta-system operation is also getting new. Due to the complex structure, possible conflicts, and competition in this meta-system, the classic hierarchical principle of integrated energy systems control fails to deliver on the targets they share. The new system design should combine certain independence of multiple decision-making centers and their coordination in ensuring reliable energy supply to consumers. It should be based on the principles of subsidiarity (ability to delegate control functions to the system levels remote from the center) and self-regulation, according to which control is implemented from the inside instead of by acting on the controlled system from the outside. The implementation of this principle presupposes arranging the interaction of agents with each other, which results in the introduction of internal control factors. At the same time, the systems have their own control, goals, and tasks and operate relatively independently, coordinating themselves with other systems by pursuing a common target.

These provisions predetermine a network model of relationships, based on the principle of complementarity, where the actions of one participant in achieving their tasks simultaneously contribute to achieving certain tasks of other participants. The architecture of integrated intelligent energy systems is shown in Fig.9. The network organization is a principle of higher order in comparison with the existing hierarchical subordinate structure of energy systems control.

As a result of the integration of energy systems into a higher level meta-system, the old properties get enhanced, while the new ones manifest themselves, among which the most significant are: flexibility; intelligent nature; integration; efficiency; competitiveness; reliability; complementarity in the performance of a shared task; unity of principles of organization and operation, and independence in the implementation of local functions. This generates new tasks for the management and control of integrated intelligent infrastructure systems of the energy industry.

\section{B. Cyber-physical energy systems of the future}

Modern energy infrastructure systems (EPS, HS, and GSS) are the entities of utmost complexity in terms of their structure operation, with each of them being made up of two closely interconnected subsystems: physical (process) and information-and-communication (ICS) subsystems. Already at present, and even more so in the future, the process and information-and-communication subsystems are getting comparable in complexity and responsibility in terms of ensuring the normal operation of each of these subsystems.

Currently, the digitalization of the above integrated intelligent infrastructure systems of the energy sector is being actively carried out. It implies not only the acceleration of information processing in digital form but also an increase in the efficiency of technological processes in energy systems due to optimal intelligent control of processes. These, as well as the noted factors of ICS complexity and responsibility, predetermine the necessity to treat EPSs, HSs, and GSSs as complex cyber-physical systems [15, etc.].

Within such systems, the ICS can operate inadequately due to internal defects (errors in algorithms, etc.) and can also be exposed to unauthorized external impacts (cyber attacks) [16, etc.]. Taking into account internal and, especially, external factors (cyber attacks) the problem of cybersecurity becomes urgent $[17$, etc. $]$. 
Reliability of information on the current state of the energy system or its loss due to internal defects of digital devices or external cyber attacks on the ICS may be the reason for working out and implementing incorrect control actions and unfolding of the emergency process in the physical subsystem. In turn, a failure or accident of an element in a physical subsystem may not only cause an emergency in that subsystem but may also contribute to the failure of the ICS elements. Taking into account these interrelationships, the integration of physical and information-and-communication factors should be implemented at the level of substantiation of the development of cyber-physical energy systems, as well as in solving various problems of controlling their operation modes.

Thus, for the present, and even more so for the future, cyber-physical energy systems, the scope of factors that largely determine the transformation of the structure and properties of energy systems and form a list of relevant problems for research and ensuring the flexibility and survivability (resiliency) of these systems is drastically expanding.

\section{DIRECTIONS OF CONTROL SYSTEMS DEVELOPMENT FOR INTEGRATED ENERGY SYSTEMS}

\section{A. Electric power systems}

The presented analysis of the transformation of the structure and properties of future EPSs testifies to the key role of control in ensuring the normal operation of these cyber-physical systems. Taking into account the growing complexity of processes that take place in EPSs, control systems should match them in their developments. Forecasts that deal with this direction indicate that future EPS control systems should have a hierarchical structure $[18$, etc.]. To counteract the development of cascade accidents, the need for coordinated hierarchical control is discussed. The important role of artificial intelligence methods in improving control efficiency is formulated. The ideology of Wide Area Monitoring, Protection, and Control Systems based on vector measurements with the prediction of state variables to ensure adaptive control is developed. It is typical for electricity storage devices, FACTS devices, etc. for control purposes.

In the above plan, the currently operating and developing highly efficient system of automatic emergency control of EPSs of Russia including the key hierarchical subsystem of adaptive emergency control automatics [19, etc.] should be represented. The lower level covers microprocessorbased automatic devices that implement specific control actions, which are cyclically adjusted at the upper level, thus providing adaptive control. The multi-tier principle of automatics operation is realized: if at the first stage automatics failed to ensure maintaining of stability of the EPS, the next group of automatic devices counteracting the cascade development of accident comes into operation.
The above tenets of the transformation of EPS control systems are mainly related to the level of super-systems and can be considered as a baseline for mini-systems. The ideology of control systems of micro-systems on a multiagent basis with the aid of consensus control algorithms when using appropriate protocols of the interaction of agents in the process of control is actively developed [20, etc.].

\section{$B$. Heating systems}

The fundamental thesis for HSs that is implemented as a result of their technological transformation, is the transition from a qualitative method of regulation of heat supply to a quantitative method of its supply. This radically changes the organization of systems and the principles of control of their thermal and hydraulic modes. The availability of automatic equipment, intelligent systems, and the horizontally-organized control structure ensures the control of heating in accordance with the needs, increases the efficiency of HSs while improving the quality of performing their functions.

Consumers are increasingly beginning to exercise active load control functions. They assume a part of the tasks aimed at creating comfortable conditions delegated to them by centralized control structures. Active consumers not only manage their power consumption mode but also influence the operation of the HS as a whole. If they have their own heat source, they can provide heat not only to meet their own heat needs but also to meet the demand for heat by neighboring consumers. The presence of such consumers in the HS expands the functionality of the systems, creates the necessary conditions for controlling the reliability of their heating, and enhances resiliency.

For many years, computational and optimization computer models have been and continue to be used to control the development and operation of HSs, as well as other energy systems. With the development of information and hardware technologies as well as methods of computational mathematics, they were transformed into their digital doubles with a wider range of information and intellectual resources. They represent digital models of the interconnected elements of the HS and are used for remote information acquisition, its processing, and control of operation modes of heat sources, heating networks, and ensuring heat load profiles of consumers with automatic monitoring and maintenance of comfortable indoor temperature. At the same time, there are new opportunities emerging for controlling heating systems, improving efficiency, timely identification and localization of damage locations in visually unobservable heat networks distributed over a large area, assessment of causes of excess heat losses, prioritization within repair schedules, etc.

Many energy companies, such as Gazprom Energoholding, are already implementing services of online applications for contracts, exchange of billing documents, and online payment for consumed heat. The automated 
system of heat energy metering is being implemented, which allows automatic collecting and storing the readings coming from the metering units, as required for analysis and monitoring of heating parameters. Their processing, digital structural representation for integration into automated complexes of dispatching control of systems operation is being carried out.

\section{Gas supply systems}

Just like with electric power systems, in connection with the global intellectualization of the GSS, there are certain fears associated with the increased vulnerability of the system given the negative impact of the intellectual nature of cyber attacks. In this case, the task of reducing GSS vulnerability should be solved simultaneously with the growth of the system's intellectualization. This can be done from the standpoint of the developing information technology and administration of the corresponding systems, as well as from the perspective of improving the optimality of dispatch control in the event of emergencies of various nature. One should provide for the possibility of switching over individual process operations and logical chains thereof to the "manual" control mode with the return back to the mode of the interconnected intellectual operation following the elimination of possibilities of threat realization.

Intelligent dispatching control systems of the GSS should have a hierarchical structure with independent modules of individual facilities and subsystems, linked into a single control system. At the super-system level, dispatching of strategic processes in each element and the GSS as a whole is implemented, starting from the main compressor stations at the field outlets and down to the points of its delivery to gas distribution stations and units, natural gas liquefaction plants with the corresponding infrastructure, gas carriers, and regasification terminals.

The same control ideology should apply to the level of gas distribution systems (the level of mini-systems in the GSS). As for the operation of gas supply systems inside buildings, structures, industrial enterprises of different levels, the control systems of the micro-level GSS fit nicely into the ideology of intelligent systems of "smart" houses and enterprises that are nowadays being developed and put into operation. Gas supply control systems of this level of the GSS will be actively developed inseparably from the directions and rates of intellectualization of control of internal utility systems of buildings and structures in direct connection with unified dispatching centers of the minisystems level.

\section{CONCLUSION}

The development of infrastructure energy systems on the basis of technology innovations in physical and information-and-communication subsystems under digitalization and intellectualization of operation processes will lead to the decisive transformation of the structure and properties of these systems. As a result, future energy systems will take the form of elaborate intelligent cyberphysical systems, radically different from the systems of today. This transformation will require a significant reconsideration of the existing principles and methods of modeling such systems, analysis of their new properties, justification of their development and control of their operation. The basis of new methods and models, along with the traditional ones, should become the proven-tobe-effective apparatus of artificial intelligence. The key role in ensuring the normal operation of the transforming energy systems will be played by future control systems, the ideology behind construction and operation of which should be ahead of the needs of the transforming cyberphysical systems.

\section{AKNOWLEDGEMENT}

This study was supported by grant \# III.17.4.1 (AAAA-A17-117030310432-9) of State Program for Basic Researches 0f Siberian Branch of Russian Academy of Sciences

\section{REFERENCES}

[1] N. I. Voropai., V.A. Stennikov "Integrated intelligent energy systems", Izvestiya RAN. Energetika, 2014, no. 1 , pp. 64 - 72 (in Russian)

[2] F. Opadchiy "The need for large energy systems is not decreasing, but increasing", Elektroenergiya. Peredacha i raspredelenie, 2020, no. 1(58), pp. 146 - 150 (in Russian)

[3] G. Strbac, D. Pudjianto, M. Aunedi, e. a. "Costeffective decarboni-zation in a decentralized market", IEEE Power and Energy Magazine, 2019, vol. 17, no. 2, pp. $25-36$.

[4] Liu Zhenya, "Global energy interconnection", Amsterdam e. a., Elsevier, 2015, 379 p.

[5] M. Amin, "Challenges in reliability, security, efficiency, and resilience in energy infrastructure: Toward smart self-healing electric power grid", IEEE PES General Meeting, Pittsburg, USA, 2008, 5 p.

[6] N.I. Voropai, B. Bat-Undral, E. Enkhsaikhan, "Directions and problems of development of micro power supply systems of isolated consumers in Mongolia", Izvestiya RAN. Energetika, 2019, no. 6, p. 43 - 50 (in Russian)

[7] World Energy Outlook 2019 / https://www.iea.org/ reports/world-energy-outlook-2019/gas.

[8] BP Energy Outlook 2019 edition / https:/www.bp.com/ content/dam/bp/business-sites/en/global/corporate/ pdfs/energy-economics/energy-outlook/bp-energyoutlook-2019.pdf и др.

[9] https://www.exxonmobil.ru/ru-RU/Energy-andtechnology/Energy/Natural-gas/Plans-to-expand-theGolden-Pass-terminal-could-generate-up-to-45000jobs-nationwide и др.

[10] Frozen heat a global outlook on methane gas hydrates https://sustainabledevelopment.un.org/content/ documents/1993GasHydrates_Vol2_screen.pdf 
[11] Modern Perspective on Gas Hydrates https://www. usgs.gov/news/modern-perspective-gas-hydrates etc.

[12] They got what they wanted. JOGMEC of Japan conducted the first production of natural gas tapped from deposits of methane hydrates https://neftegaz. ru/news/gas/210223-dobilis-svoego-yaponskayajogmec-poluchila-1-yu-partiyu-prirodnogo-gaza-izgidratov-metana/ и др. (in Russian)

[13] N.I. Voropai, Ch. Rehtanz, "Flexibility and resiliency of electric power systems: Analysis of definitions and content", EPJ Web of Conferences. International Workshop on Flexibility and Resiliency of Electric Power Systems, Irkutsk, Russia, 2019, 6 p.

[14] M. Kezunovic, T.J. Overbye, "Off the beaten path: Resiliency and associated risk", IEEE Power and Energy Magazine, 2018, vol. 16, no. 2, pp. 26 - 35.

[15] S. Mehrdad, S. Mousavian, G. Madraki, "Cyberphysical resilience of electric power systems against malicious attacks: A review", Current Sustainable/ Renewable Energy Reports, https://doi.org/101007/ s40518-018-0094-8

[16] S.K. Khaitan, J.D. McCalley, "Cyber physical system approach for design of power grids: A surwey", 2013 IEEE PES General Meeting, Vancouver, Canada, 2013, 5 p.

[17] J. Hull, H. Khurana, T. Markham, K. Staggs, "Staying in control: Cybersecurity and the modern electric grid", IEEE Power and Energy Magazine, 2012, vol. 10, no. 1, pp. $41-48$.

[18] B. Fardanesh, "Future trends in power system control", IEEE Computer Application in Power, 2002, vol. 15, no. 3 , pp. $24-31$.

[19] A.S. Gerasimov, L.A. Koshcheev, V.A. Kritskij, A.A. Lisitsin, "Automatic emergency control in power systems", Elektricheskie stancii, 2020, no. 1, pp. 41 - 49 (in Russian)

[20] R. Olfati-Saber, J.A. Fax, R.M. Murray, "Consensus and cooperation in networked multi-agent systems", Proceedings of the IEEE, 2007, vol. 95, no. 1, pp. 215 $-233$.

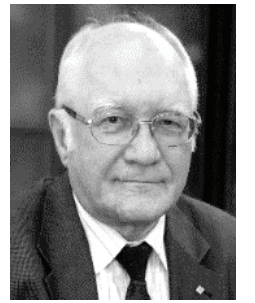

Nikolai Voropai is Professor, President of Melentiev Energy Systems Institute of the Russian Academy of Science, Irkutsk, Russia. He is the Corresponding Member of the Russian Academy of Sciences.

He graduated from Leningrad (St. Petersburg) Polytechnic Institute in 1966. N.I. Voropai received his degrees of Candidate of Technical Sciences at the Leningrad Polytechnic Institute in 1974 and Doctor of Technical Sciences at the Siberian Energy Institute in 1990. His research interests include modeling of power systems operation, dynamics performance and control of large power grids; reliability and security of power systems; development of national, international and intercontinental power grids; smart grids; power industry restructuring.

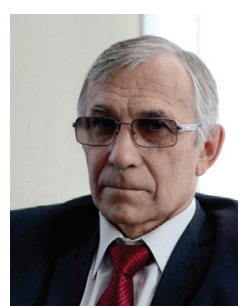

Valery Stennikov is Professor, Director of the Melentiev Energy Systems Institute of Siberian Branch of the Russian Academy of Sciences, Corresponding Member of the Russian Academy of Sciences. He received his Candidate of Engineering Sciences degree in 1985 and the Doctor of Engineering Sciences degree in 2002. (according to the Russian system of doctoral level scientific degrees). His research interests include the methodology, mathematical models and methods for the development of heating systems in terms of reliability and controllability requirements; energy effective technologies and equipment; energy saving; methods and algorithms for calculation of heat tariffs; intelligent integrated energy system.

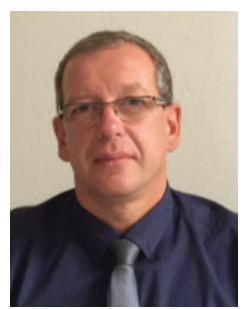

Sergey Senderov graduated from Irkutsk Technical University in 1986. He is a Professor, Head of Energy Security Department and Deputy Director of the Melentiev Energy Systems Institute of Siberian Branch of the Russian Academy of Sciences. His research interests are energy security, threats and indicators of energy security, reliability of energy systems and of fuel-energy supply. 